\title{
Cámara y modelo. Fotografía de maquetas de arquitectura en España, 1925-1970 / Modelling for the Camera. Photography of Architectural Models in Spain, 1925-1970
}

\author{
BERGERA, Iñaki (ed.) \\ Fundación ICO, La Fábrica D. L., Madrid, 2016
}

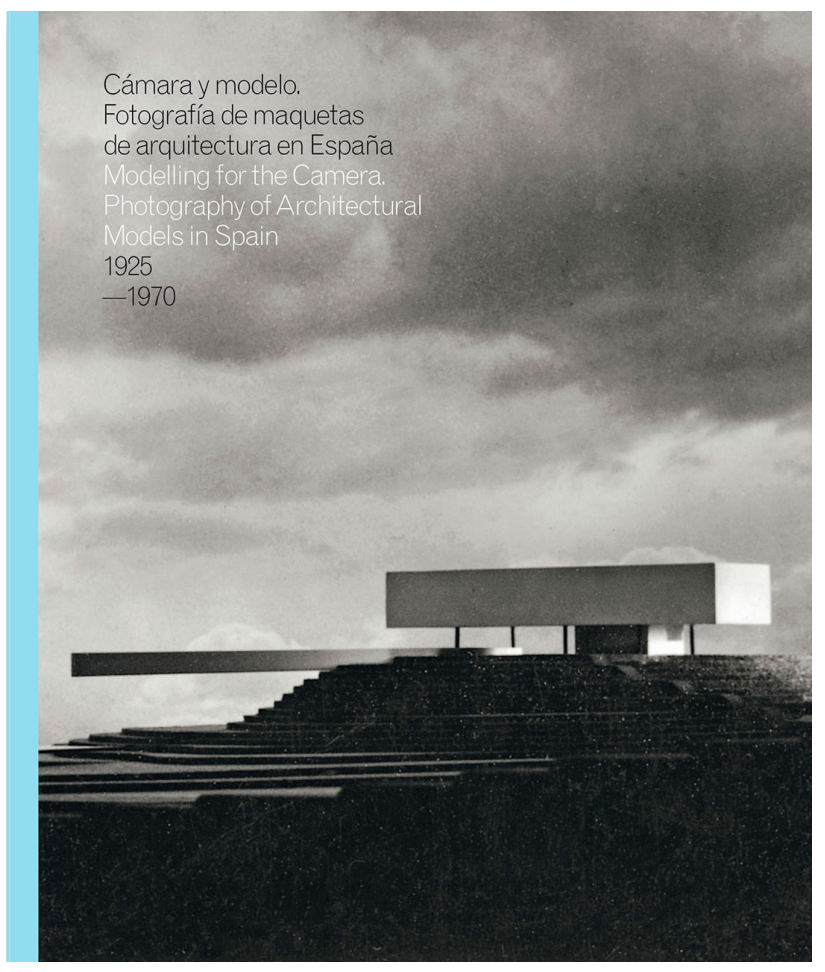

Cámara y modelo. Fotografía de maquetas de arquitectura en España, 1925-1970 es el catálogo de la exposición homónima que albergó el Museo ICO de Madrid entre febrero y mayo de 2017. Este libro se suma al amplio número de actividades del proyecto de investigación del Ministerio de Economía y Competitividad (MINECO) sobre Fotografía y Arquitectura Moderna en España (FAME) que lidera su investigador principal, Iñaki Bergera, desde la Escuela de Ingeniería y Arquitectura de la Universidad de Zaragoza, y que cuenta con la colaboración de dieciocho investigadores de diez universidades españolas y una institución extranjera. Bergera, comisario de la exposición y editor de este libro, nos presenta nuevamente ese satisfactorio matrimonio que es la arquitectura moderna y su representación en imágenes, esta vez de maquetas de edificios tanto construidos como no construidos. El valor artístico intemporal de las más de cien imágenes de los modelos seleccionados avala el trabajo documental realizado por todos los investigadores del proyecto que, además, reconoce la actividad creativa de más de una decena de fotógrafos, algunos amateurs, otros profesionales, y de arquitectos que amaron una disciplina todavía no reconocida como arte en la España de la época, como Català-Roca, Kindel, Pando, Lladó, Maspons-Ubiña y Gómez, o Aizpurua, de la Sota, Higueras, Sert, Fisac o Carvajal.

Además de señalar el vacío historiográfico que existe en torno a este tema, el ensayo introductorio de Bergera destaca el escaso reconocimiento que la historia ha dado a los constructores de las maquetas fotografiadas, que alejados de los actuales medios digitales fueron esenciales para materializar los deseos de los arquitectos. «En las décadas de la vanguardia y consolidación del Movimiento Moderno, las maquetas, y las fotografías, se hacían con la mano y, muchas veces, cabían en ella. Cuanto más pequeña es la maqueta, más concentrado y con más precisión se expresa su concepto», escribe Bergera. Entre otros, se destaca la figura de Jordi Brunet como uno de los maquetistas más destacados, al ser colaborador habitual desde la década de 1950 de algunos de los «mejores arquitectos de aquellos años como J. Sotreas, F. Mitjans, F.J. Sáenz de Oíza, A. Bonet, C. de Miguel, A. Lamela, F. Higueras o A. Perpiña, entre otros».

El libro se complementa con tres textos, de Davide Deriu (Universidad de Westmister, Londres), Juan Carlos Oliver Torelló (Universitat de les Illes Balears) y Eduardo Prieto (Universidad Politécnica de Madrid), que revisan el papel que han tenido los modelos de edificios a lo largo de la historia de la arquitectura. Los autores se remontan al Renacimiento para recordarnos la relevancia de las maquetas de arquitec- 
tura en el Quattrocento y el Cinquecento italiano. A través de reflexiones de Alberti, Vasari o Scamozzi, Eduardo Prieto revisa el valor que uno u otro dieron a las maquetas, entonces de madera, esencialmente utilizadas como herramientas de mediación entre los ideales humanistas del momento y la construcción, como es el caso de la conocida maqueta de Brunelleschi para la cúpula de Santa Maria del Fiore en Florencia. Por otro lado, Deriu y Oliver analizan el declive que sufrió este medio en el siglo XIX y su espectacular reaparición a comienzos del siglo XX ligada al «giro del Movimiento Moderno hacia la nueva objetividad» y al «rechazo de las vanguardias hacia los sistemas de representación e ideación vinculados a las prácticas academicistas». La búsqueda de modos económicos y prácticos para comunicar ideas proyectuales supuso que materiales livianos como el cartón se hiciesen un hueco indispensable en tiempos de escasez. Según argumenta Deriu, la maqueta de arquitectura no reapareció de manera aislada, sino que coincidió con el papel destacado y creciente del arte de la fotografía. Ambos medios se cruzaron creando imágenes fundamentales en el repertorio iconográfico de la modernidad.

Desde diferentes perspectivas, los textos reflexionan en torno al componente pedagógico de las fotografías de maquetas de arquitectura y su continuado uso en escuelas de arquitectura de vanguardia de comienzos del siglo XX, como la Bauhaus o el Vjutemas. Deriu, por un lado, señala que las maquetas y su fotografiado promueven la exploración creativa del espacio, la forma y el volumen, y también, ayudan a retratar el proceso proyectual del proyecto, en ocasiones acompañado con sencillos fotomontajes -fotografías de maquetas manipuladas junto a imágenes de paisajes o ciudades-. Así, la fotografía de maquetas se torna una alternativa al dibujo y a otras herramientas gráficas clásicas del diseño de edificios. Oliver Torelló, por su parte, incide en el valor educativo de las maquetas y puntualiza que «estos modelos fotografiados, como "construcciones espaciales» o "ejercicios de equilibrio y de material», a medio camino entre los valores escultóricos y los arquitectónicos, mantenían una clara relación con su posterior representación fotográfica, que servía de herramienta para valorar los aspectos volumétricos, materiales o cinéticos de la composición». Con ello, la fotografía de modelos fomentó una percepción volumétrica de la arquitectura, con ejemplos canónicos como el proyecto de graduación de
Ivan Leonidov para un instituto y una biblioteca dedicados a Lenin en Moscú o el proyecto de Rascacielos de vidrio de Mies van der Rohe para Berlín. En suma, los autores coinciden en otorgar a la maqueta y su imagen un valor icónico, en ocasiones como objeto de fervor religioso, en otras como fetiche del arquitecto o, incluso, como propaganda política. Asimismo, entienden que en la modernidad su valor iconográfico se suma a su valor como experimento, como herramienta de trabajo para ese arte de vanguardia que era diseñar la «nueva arquitectura».

Los cuatro ensayos citados preceden a la selección de fotografías provenientes de diferentes archivos españoles que destacan, entre otras razones, por su belleza. Muchas de las fotografías de maquetas reproducidas en este libro son hitos construidos y no construidos de la cultura arquitectónica moderna española, y, además, son iconos en sí mismas; desde la imagen de Luis Lladó que retrata la maqueta de trabajo que Secundino Zuazo y Eduardo Torroja realizaron para estudiar el espacio interior del Frontón Recoletos de Madrid en 1932, hasta la fotografía que el propio Alejandro de la Sota tomó para plasmar su propuesta para el edificio Bankunión, también en Madrid, en 1970. El libro se complementa con fotografías de los propios arquitectos junto a sus modelos, de Juan Antonio García Solera observando en 1963 su maqueta para la urbanización Maralic en Alicante, de Emilio Pérez Piñero junto a su cúpula desplegable integral, también de comienzos de los sesenta, entre otras. Junto a su incuestionable valor plástico, estas imágenes insisten en esa idea del modelo de arquitectura como fetiche en torno a la que reflexiona Eduardo Prieto en su ensayo.

Las instantáneas reproducidas en este libro se caracterizan, además, por utilizar recursos fotográficos que vienen de la mano de la «nueva fotografía» desarrollada en el periodo de entreguerras. Si consensuar lo moderno de la arquitectura fue el trabajo esencial de la historiografía de la arquitectura moderna española esencialmente publicada a partir de los años sesenta, una vez logrado esto, la selección de fotografías mostrada en este libro se propone evidenciar la modernidad de esas imágenes, también como objetos artísticos. Mostrar la relación entre la «nueva arquitectura» y la «nueva fotografía», demostrar su dependencia mutua parece así un objetivo cumplido.

En la exposición celebrada en el Museo ICO, se acompañó a estas fotografías de una selección de maquetas 
originales que permitían valorar y reflexionar sobre el valor añadido que la fotografía aporta al objeto fotografiado, es decir, al modelo; una cuestión sobre la que reflexiona Juan Carlos Oliver en su ensayo. Es este un libro que viene a llenar un gran vacío historiográfico en la arquitectura moderna española y que, sumado a las ya varias publicaciones de su editor, sienta una base fundamental para posteriores investigaciones sobre ese feliz maridaje que es la arquitectura, su modelo y su fotografía.
Lucía C. Pérez-Moreno

Universidad de Zaragoza 